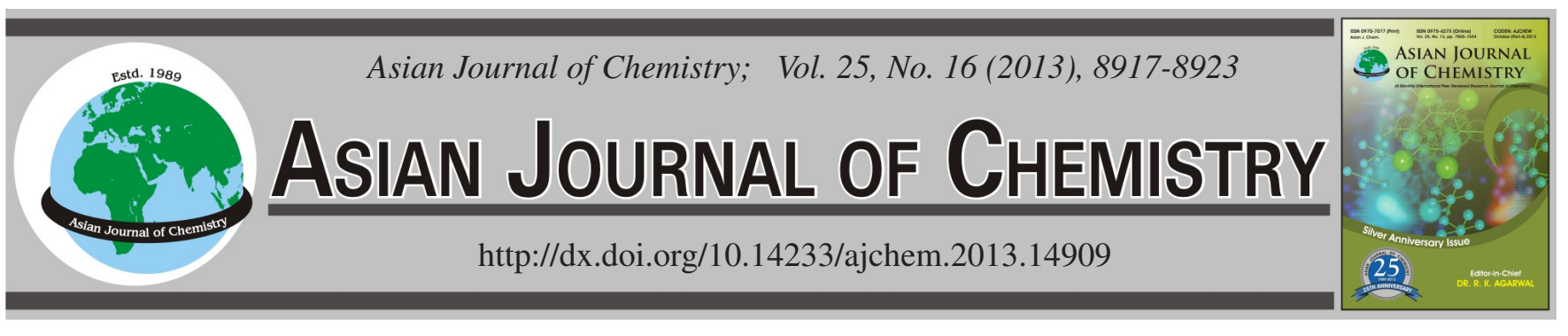

\title{
Rapid and Sensitive UPLC-MS/MS Method for Simultaneous Quantification of Peimine and Peiminine: A Multiple Drug Resistance Reversal Agent of Tumors and their Application to Preliminary Pharmacokinetic Studies in Beagle Dogs
}

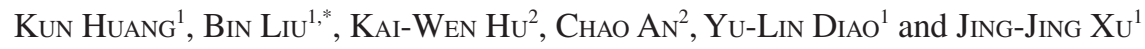

${ }^{1}$ School of Chinese Medicine, Beijing University of Chinese Medicine, Beijing 100102, P.R. China

${ }^{2}$ East Hospital, Beijing University of Chinese Medicine, Beijing 100078, P.R. China

*Corresponding author: Fax:+86 10 84738611; Tel: +86 10 84738629; E-mail: liubinyn67@163.com

(Received: 4 December 2012;

Accepted: 9 September 2013)

AJC-14080

\begin{abstract}
To establish a more comprehensive and suitable UPLC-MS/MS quantitative procedure for pharmacokinetic study of peimine and peiminine, which can be used as reversal agent of tumor multiple drug resistance, in beagle dogs. The analytes were extracted from dog plasma via solid-phase extraction method, with tetrahydropulmatine as internal standard. The chromatographical separation was accomplished on an ACQUITY UPLCTM BEH C $\mathrm{C}_{18}$ column $(50 \mathrm{~mm} \times 2.1 \mathrm{~mm}$ i.d., $1.7 \mu \mathrm{m})$ with a gradient mobile phase of acetonitrile and water $(10 \mathrm{mmol} / \mathrm{L}$ ammonium bicarbonate using ammonia water adjusting $\mathrm{pH}=10$ ) at a flow rate of $0.25 \mathrm{~mL} / \mathrm{min}$. The identification and detection of target compounds were achieved under multiple reactions monitoring mode with positive electrospray ionization. The linear ranges of the calibration curves for peimine and peiminine are $1-600 \mathrm{ng} / \mathrm{mL}\left(\mathrm{r}^{2}>0.99\right)$. The specificity, precision, accuracy, extraction recovery, matrix effect and stability were all in the acceptable ranges. The procedure established herein is more sensitive, specific and validated for the quantitation of peimine and peiminine in dog plasma and can be successfully applied to pharmacokinetic study in beagle dogs.
\end{abstract}

Key Words: Peimine, Peiminine, UPLC-MS/MS, Pharmacokinetics, Beagle dog.

\section{INTRODUCTION}

Multidrug resistance of tumor cells to chemotherapeutic agents is the main reason for the treatment failure in cancer chemotherapy. The current resistance reversal agents of cancer cells have several defects, such as high toxicity, serious adverse reactions and single mechanism of action ${ }^{1-7}$. Searching for safe and effective multidrug resistance reversal agents have become a popular field of cancer drug development. Chinese herbal medicine is widely used in Chinese clinical cancer therapy because of its multi-component and multi-mechanism advantages. Bulbus fritillariae thunbergii, a traditional Chinese medicine with diverse pharmacological effects ${ }^{8,9}$, has been widely adopted for clinical use in China for hundreds of years. Our previous research indicated that peimine and peiminine, the alkaloids of Bulbus fritillariae thunbergii, can reverse the multidrug resistance of cancer cells ${ }^{10-12}$. As the first reported steroidal alkaloids with this activity, these two chemical constituents with multi-mechanism characteristics have fewer side reactions and better efficacy compared with other reversal agents ${ }^{10}$.

Determining the in vivo pharmacokinetic profile of peimine and peiminine to illustrate their reversal mechanism is urgently needed. However, the lack of analytical method for determination restricted the implementation of this experiment. In the current study, a rapid and sensitive procedure for quantifying peimine and peiminine in dog plasma as well as a new and reliable plasma preparation technique were developed. Furthermore, this study was the first pharmacokinetic study of Bulbus fritillariae thunbergii viewed as resistance reversal agents of cancer cells. This research will provide the basic experimental data for the follow-up study on Bulbus fritillariae thunbergii.

\section{EXPERIMENTAL}

Samples were analyzed using an ACQUITY UPLC system (Waters Corp., Milford, MA, USA) coupled with a Quattro Premier XETM triple quadruple mass spectrometer (Waters Corp., Milford, MA, USA). The UPLC system consists of a quaternary pump, an autosampler and a column oven. Chromatographic separation was performed on a $\mathrm{BEH} \mathrm{C}_{18}$ column (50 $\mathrm{mm} \times 2.1 \mathrm{~mm}$ i.d., $1.7 \mu \mathrm{m}$ particle size) with a gradient elution of mobile phase system consisting of acetonitrile (A) and $10 \mathrm{mM}$ HPLC grade ammonium bicarbonate (adjusted to pH 10 by ammonia water) (B). The elution was carried out based on the following time program: $0 \mathrm{~min}$ to $0.5 \mathrm{~min}, 80 \%$ 
to $32 \% \mathrm{~B} ; 0.5 \mathrm{~min}$ to $2.0 \mathrm{~min}, 32 \%$ to $10 \% \mathrm{~B} ; 2.0 \mathrm{~min}$ to 3.0 $\min , 10 \% \mathrm{~B} ; 3.0 \mathrm{~min}$ to $4.0 \mathrm{~min}, 10 \%$ to $80 \% \mathrm{~B}$. The flow rate was set at $0.25 \mathrm{~mL} / \mathrm{min}$. The temperatures of the column and autosampler were kept constant at $25^{\circ} \mathrm{C}$ and $10{ }^{\circ} \mathrm{C}$, respectively. The injection volume was $5 \mu \mathrm{L}$.

Peimine (purity $>98 \%$ ), peiminine (purity $>98 \%$ ) and tetrahydropalmatine (I.S.) were purchased from National Institutes for Food and Drug Control (Beijing, China). HPLCgrade acetonitrile and methanol were provided by Merck (Merck Company, Germany). Other chemicals were all analytical grade. Ultrapure water was generated from a Milli-Q system (Millipore, USA).

Mass spectrometric conditions: A triple quadruple tandem mass spectrometer equipped with electrospray ionization interface was operated in positive mode for analytic detection. Data were collected using multiple reactions monitoring mode. The mass spectrometric (MS) condition was determined by the response of analytes with precursor/product ion transitions of $\mathrm{m} / \mathrm{z} 432.5 \rightarrow 414.4$ for peimine, $\mathrm{m} / \mathrm{z} 430.5$ $\rightarrow 412.4$ for peiminine and $m / z \quad 356.3 \rightarrow 192.0$ for I.S. The MS parameters were set as follows: capillary voltage, $3.0 \mathrm{kV}$; extractor voltage, $3.0 \mathrm{~V}$; RF lens, $0.3 \mathrm{~V}$; source temperature, $100{ }^{\circ} \mathrm{C}$; desolvation temperature, $350{ }^{\circ} \mathrm{C}$; desolvation gas (nitrogen) flow, $600 \mathrm{~L} / \mathrm{h}$; and collision gas (argon) flow, 0.15 $\mathrm{mL} / \mathrm{min}$. The cone voltage and collision energy were optimized to maximize the intensity of transition ions for peimine, peiminine and I.S. Analyte-specific cone voltages, collision energies and multiple reactions monitoring transitions are provided in Table-1. The detection conditions were as follows: inter channel delay of $0.02 \mathrm{~s}$ and dwell time of $0.07 \mathrm{~s}$. All operations, acquisition and data analysis were controlled by the Masslynx V4.1 software.

\begin{tabular}{lcccc}
\hline \multicolumn{5}{c}{ TABLE-1 } \\
$\begin{array}{l}\text { COMPOUNDS DEPENDENT PARAMETERS FOR PEIMINE, } \\
\text { PEIMININE AND I.S. IN MRM MODE FOR } \\
\text { UPLC-MS/MS ANALYSIS }\end{array}$ \\
\hline Analyte & {$[\mathrm{M}+\mathrm{H}]^{+}$} & $\begin{array}{c}\text { Production } \\
\text { ion }\end{array}$ & $\begin{array}{c}\text { Cone } \\
\text { voltage }(\mathrm{V})\end{array}$ & $\begin{array}{c}\text { Collision energy } \\
(\mathrm{eV})\end{array}$ \\
\hline Peimine & 432.5 & 414.4 & 27 & 30 \\
Peiminine & 430.5 & ${ }^{1} 412.4$ & 35 & 35 \\
I.S. & 356.3 & 192.0 & 35 & 20 \\
I.S. & 356.3 & 164.8 & 35 & 20 \\
\hline 'Production ion was for quantitative analysis
\end{tabular}

Standards preparation: Stock solutions of peimine, peiminine and I.S. were prepared in methanol to yield concentrations of $6 \mu \mathrm{g} / \mathrm{mL}, 0.6 \mu \mathrm{g} / \mathrm{mL}$ and $60 \mathrm{ng} / \mathrm{mL}$, respectively. Standard solutions with concentrations of 10, 60, 120, 300, $600,1500,3000$ and $6000 \mathrm{ng} / \mathrm{mL}$ were prepared from the stock solutions of peimine and peiminine via serial dilution with methanol. I.S. standard solutions with concentration of $6 \mathrm{ng} /$ $\mathrm{mL}$ were prepared from the $60 \mathrm{ng} / \mathrm{mL}$ I.S. stock solutions. All the stock and working standard solutions were stored at approximately $4{ }^{\circ} \mathrm{C}$.

Quality control samples preparation: The prepared working standard solutions of peimine, peiminine and I.S. were used to prepare quality control samples. Appropriate volumes of peimine and peiminine were added to the dog plasma to produce solutions with concentrations of 6,60 and $600 \mathrm{ng} /$
$\mathrm{mL}$. The quality control samples were immediately frozen at $-80{ }^{\circ} \mathrm{C}$ until analysis.

Plasma sample preparation: Solid phase extraction was carried out using Oasis HLB 30-mg extraction cartridges (Waters, Milford, MA, USA). The HLB cartridges were conditioned and equilibrated with $3 \mathrm{~mL}$ of methanol followed by $3 \mathrm{~mL}$ of distilled water before use. After thawing, $100 \mu \mathrm{L}$ of plasma sample spiked with $100 \mu \mathrm{L}$ of I.S. $(60.0 \mathrm{ng} / \mathrm{mL})$ was vortexed with $20 \mu \mathrm{L}$ ammonia water and then loaded onto the preconditioned cartridges. The cartridge was washed with $1 \mathrm{~mL}$ of distilled water and then eluted with $1 \mathrm{~mL}$ of methanol. The methanol eluent was collected and evaporated to dryness under gentle stream of nitrogen at $45^{\circ} \mathrm{C}$. Dried residues were redissolved in $1 \mathrm{~mL}$ of methanol (HPLC grade), transferred to autosampler vials and then $5 \mu \mathrm{L}$ of the solution was injected into UPLC-MS/MS system for quantitative analysis.

Method validation: A thorough and complete validation of peimine and peiminine determination in dog plasma was validated in terms of specificity, matrix effect, linearity, sensitivity, precision, accuracy, recovery and stability.

Specificity was tested by analyzing six different blank plasma samples for the exclusion of any potential endogenous and exogenous interference of either peimine, peiminine, or I.S. The samples were compared with those spiked plasma in known concentrations and with the plasma after oral administration of Bulbus fritillariae thunbergii extract powders. All the plasma were processed and analyzed according to the described procedure.

The effects of the interference caused by plasma matrix during analysis were evaluated by comparing the peak areas of the analytes spiked into blank extracted plasma with the counterparts prepared in methanol at three concentration levels (final concentrations of peimine and peiminine were 6 , 60 and $600 \mathrm{ng} / \mathrm{mL}$ ) and I.S. (6 ng/mL). Five replicates of each concentration were determined for calculating the relative standard deviations of the matrix effect.

Calibration curves were prepared by adding working solutions to blank plasma to achieve final concentrations of peimine and peiminine at 1, 6, 12, 30, 60, 150, 300 and 600 $\mathrm{ng} / \mathrm{mL}$ with $6 \mathrm{ng} / \mathrm{mL}$ of I.S. Five replicates of each concentration were analyzed. The lower limit of quantification (LLOQ) of each analyte was defined as the lowest concentration that can be quantitated reliably and reproducibly and the concentration that produced a signal-to-noise $(\mathrm{S} / \mathrm{N})$ ratio of at least 10. The lower limit of detection of the method was the concentration that produced $\mathrm{S} / \mathrm{N}$ of at least 3 , in which the analytes can be detected.

The intraday and interday precision and accuracy were evaluated by the results of the quality control samples $(6,60$ and $600 \mathrm{ng} / \mathrm{mL}$ ). Five replicates of each concentration of quality control samples were determined on the same day to assess the intraday precision and accuracy of the method. The interday precision and accuracy of peimine and peiminine were tested by analyzing the quality control samples at three concentrations performed on five separate days; five replicates of the quality control samples at every concentration level were analyzed. The precision and accuracy of the method expressed as RSD \% (relative standard division) and RE \% (relative error) varied from $3.9 \%$ to $12.5 \%$ and $-7.4 \%$ to $8.8 \%$, respectively. The results 
were both distributed in the range of $-15 \%$ to $15 \%$, indicating that the proposed procedure was accurate and reliable.

Recovery tests were performed by assaying three concentration levels $(6,60$ and $600 \mathrm{ng} / \mathrm{mL})$ of peimine and peiminine. Extraction recovery was expressed by comparing the mean peak area of the analytes spiked into plasma through the complete extraction procedure with the responses of the directly injected standards dissolved in methanol. The recovery of I.S. was determined using the same process.

The stability of peimine and peiminine was determined by analyzing three concentration levels of the replicates $(\mathrm{n}=$ 5) of the quality control samples exposed to different conditions. Short-term stability of peimine and peiminine in dog plasma was evaluated by keeping the unextracted samples at room temperature for $6 \mathrm{~h}$. Freeze-thaw stability was assessed by conducting three freeze-thaw cycles (room temperature to $-80^{\circ} \mathrm{C}$ ) over 8 days. Plasma samples were stored at $-80^{\circ} \mathrm{C}$ for 30 days to establish the long-term stability. Post-preparative stability was determined by reanalyzing the processed samples held in autosampler conditions $\left(10^{\circ} \mathrm{C}\right)$ for $12 \mathrm{~h}$.

Application to a pharmacokinetic study: Three mature beagle dogs (male, weighing $10 \mathrm{~kg} \pm 1 \mathrm{~kg}$ ) were provided by the Beijing Tongli Experimental Animals Breeding Plant (SCXK Beijing Province, 2010-0004, China). All procedures involving animals and experiments were in accordance with the regulations of experimental animal administration issued by the state committee of science and technology of the People's Republic of China. Before the administration of the extract powders of Bulbus fritillariae thunbergii (according to the developed and validated method, the content of peimine and peiminine were $30.09 \%$ and $16.82 \%$, respectively), the dogs were only supplied with water for more than $18 \mathrm{~h}$. The dogs were given intragastric administration at doses of 8.5, 10.5 and $12.5 \mathrm{mg} / \mathrm{kg}$ of extract powders of Bulbus fritillariae thunbergii. One milliliter of blood samples were drawn from the forelimb veins of the dogs into heparinized tubes before and at $0.08,0.17,0.25,0.33,0.50,0.75,1.00,1.50,2.00,4.00$, $6.00,8.00,10.00,12.00$ and $24.00 \mathrm{~h}$ after drug administration. The heparinized blood was then centrifuged at $4000 \mathrm{rpm}$ for $10 \mathrm{~min}$. The plasma samples were stored at $-80{ }^{\circ} \mathrm{C}$ until analysis. The pharmacokinetic parameters of peimine and peiminine were estimated using the non-compartmental model with the aid of PKSolver 2.0 (China Pharmaceutical University, China).

\section{RESULTS AND DISCUSSION}

The UPLC-MS/MS method with higher sensitivity and stronger specificity in quantification was better compared with the UPLC method tested in our previous work. Therefore, UPLC-MS/MS method was employed in this paper after overall consideration.

Method development: The multiple reactions monitoring conditions were developed for analyzing analytes and I.S.; each one was run separately. Parameters, such as desolvation temperature, source temperature, capillary voltage, extractor voltage, desolvation gas flow and collision gas flow, especially cone voltage and collision energy, were optimized to obtain an ideal signal response of the target compound. Finally, the mass transitions chosen for quantification were $m / z, 432.5 \rightarrow$ 414.4 for peimine (Fig. $1 \mathrm{~A}$ ), $\mathrm{m} / \mathrm{z} 430.5 \rightarrow 412.4$ for peiminine (Fig. 1B) and $m / z 356.3 \rightarrow 192.0$ for I.S. (Fig. 1C).
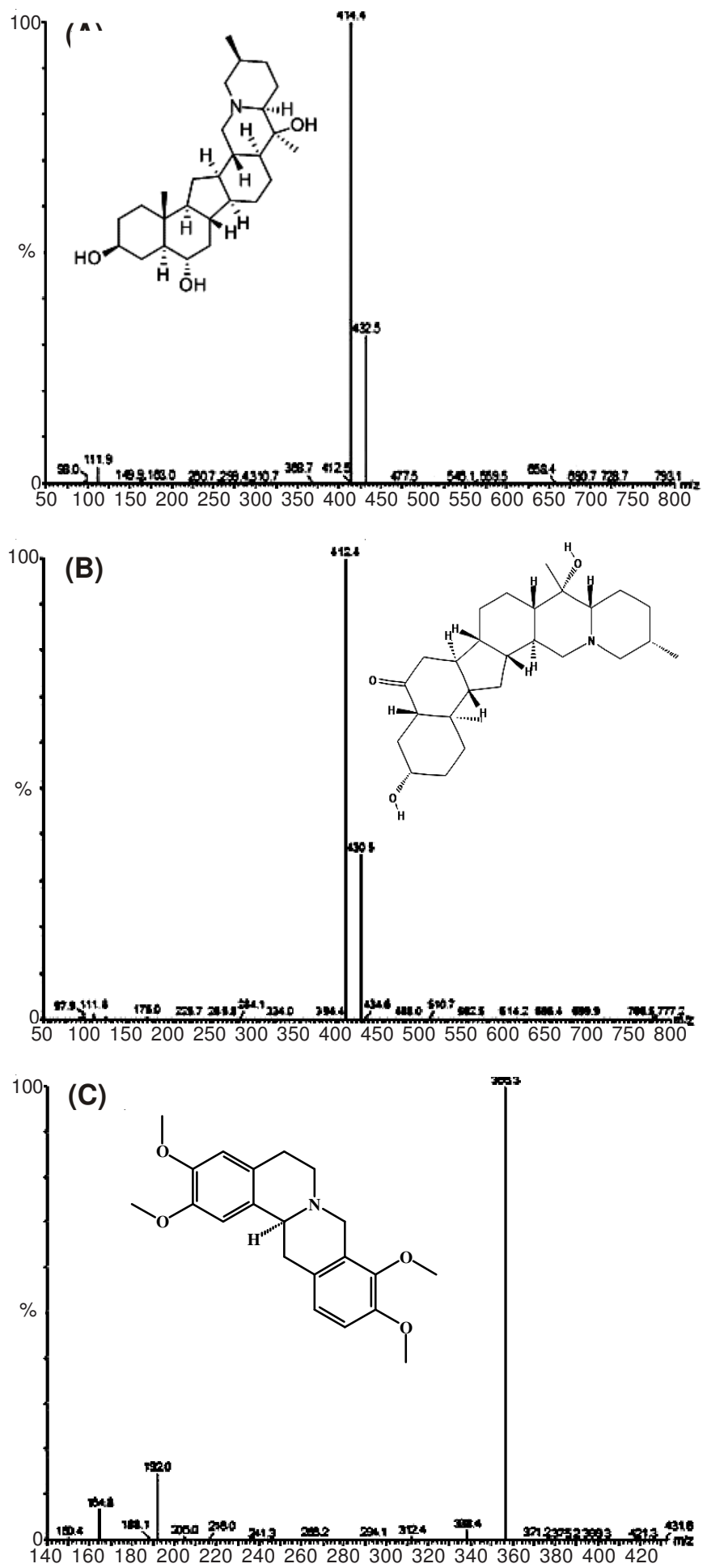

Fig. 1. Chemical structures and ESI mass scan spectra for analytes: peimine (A), peiminine (B) and I.S. (C). MS parameters: capillary voltage, $3.0 \mathrm{KV}$; extractor voltage, $3.0 \mathrm{~V}$; RF lens, $0.3 \mathrm{~V}$; source temperature, $100{ }^{\circ} \mathrm{C}$; desolvation temperature, $350^{\circ} \mathrm{C}$; desolvation gas (nitrogen) flow, $600 \mathrm{~L} / \mathrm{h}$ and collision gas (argon) flow, $0.15 \mathrm{~mL} / \mathrm{min}$

Several factors were selected for good separation and peak shape, as well as a short run time, to optimize the chromatographic conditions. First, the column style must be considered. 
A waters $\mathrm{BEH} \mathrm{C}_{18}$ column $(50 \mathrm{~mm} \times 2.1 \mathrm{~mm}$ i.d., $1.7 \mu \mathrm{m})$ was evaluated as the suitable column for analysis. The mobile phase is a crucial issue during determination of the chromatographic conditions. Various mobile phases, such as methanol-water, acetonitrile-water, acetonitrile-ammonium acetate-water and acetonitrile-ammonium bicarbonate-water, were tested. Based on the comparison, acetonitrile-ammonium bicarbonate (10 $\mathrm{mmol} / \mathrm{L}$ )-water (adjusted to $\mathrm{pH} 10$ by ammonia water) was considered as the optimal one. Under the optimum conditions determined, the analytes were free of interference from endogenous substances and the retention times of peimine, peiminine, and I.S. were 2.57, 2.79 and $1.93 \mathrm{~min}$, respectively, as shown in Fig. $2 \mathrm{C}$.

Determining an appropriate internal standard is also a crucial work. Tetrahydropalmatine was selected as I.S. because of its similarity of retention action, ionization and extraction efficiency with analytes and less endogenous interference.

Several sample pretreatment methods were investigated in the present study, such as protein precipitation (PPT), liquidliquid extraction (LLE) and solid phase extraction (SPE) to remove protein, reduce endogenous interference and improve extraction efficiency before the LC-MS/MS analysis. After comparison, PPT and LLE, the widely used methods, cannot provide satisfactory results. However, SPE was better than previously reported methods because it provides stable recovery, fewer sample loss and higher extraction efficiency. Consequently, Waters Oasis HLB $30 \mathrm{mg}$ extraction cartridges were determined in this assay. The pre-conditioned SPEs $(1 \mathrm{~mL}$ of methanol followed by $1 \mathrm{~mL}$ of water) were washed with $3 \mathrm{~mL}$ of water followed by $1 \mathrm{~mL}$ of methanol. This simple procedure developed a clean chromatogram for blank plasma samples (Fig. 2A) and yielded satisfactory recoveries of analytes and I.S. from the plasma (Fig. 2C).
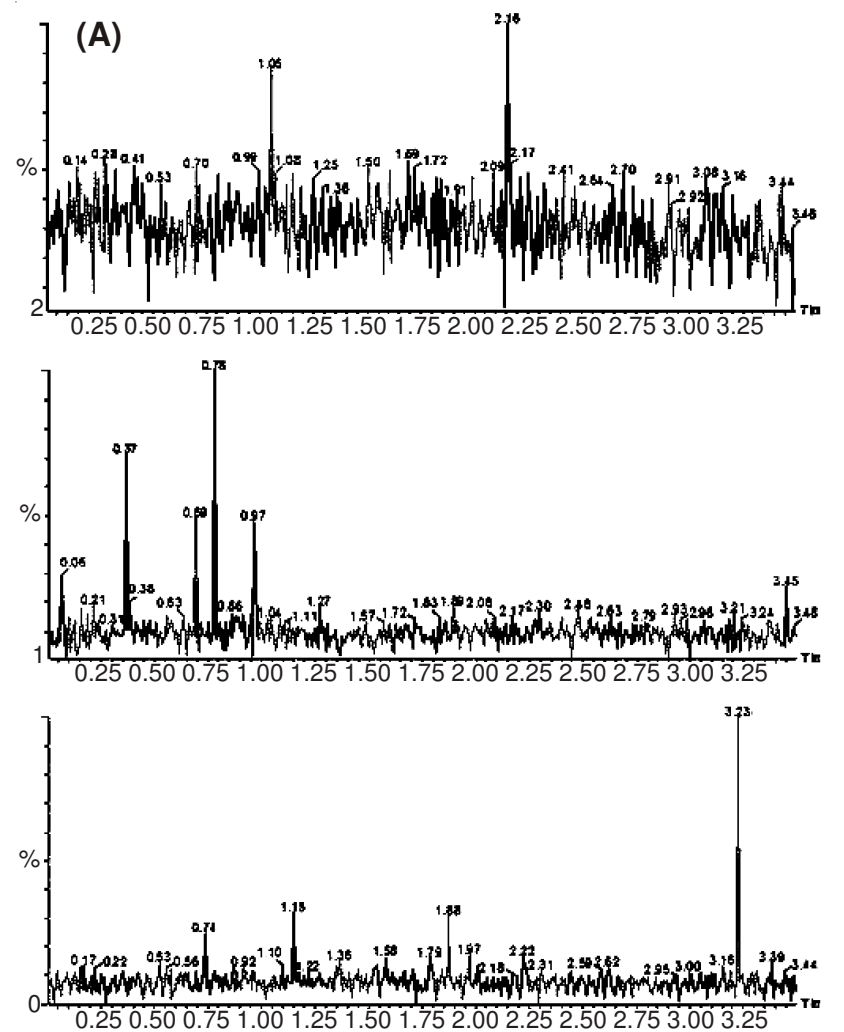
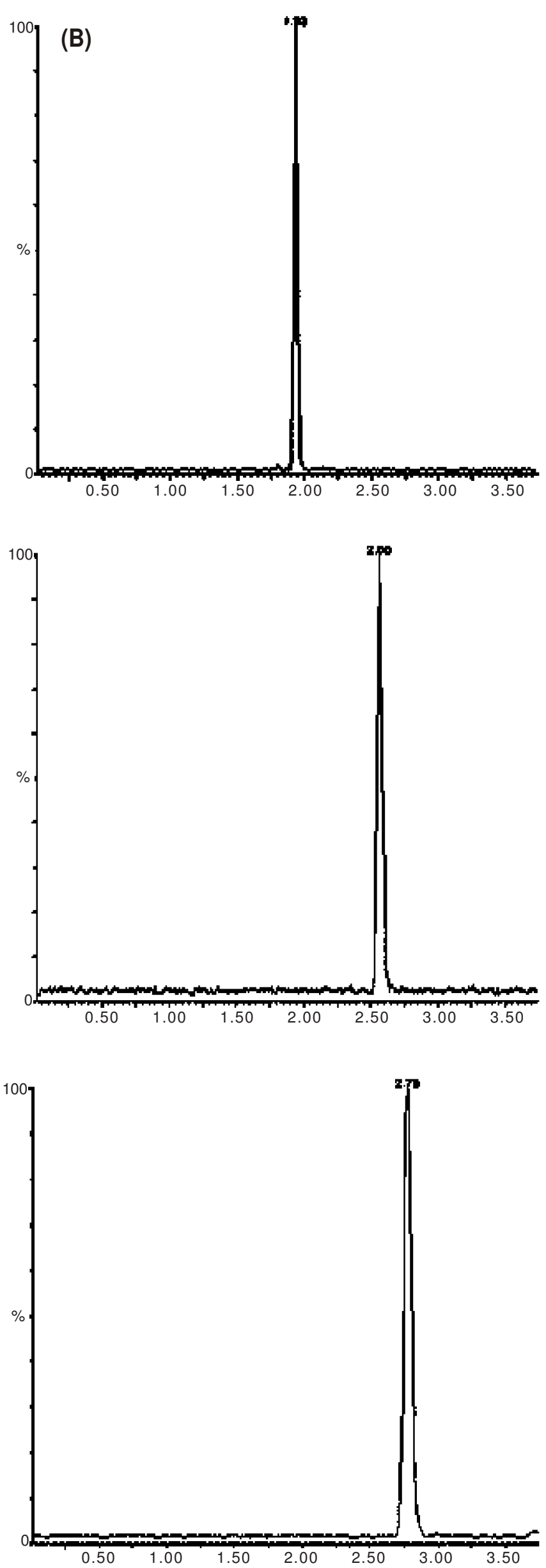

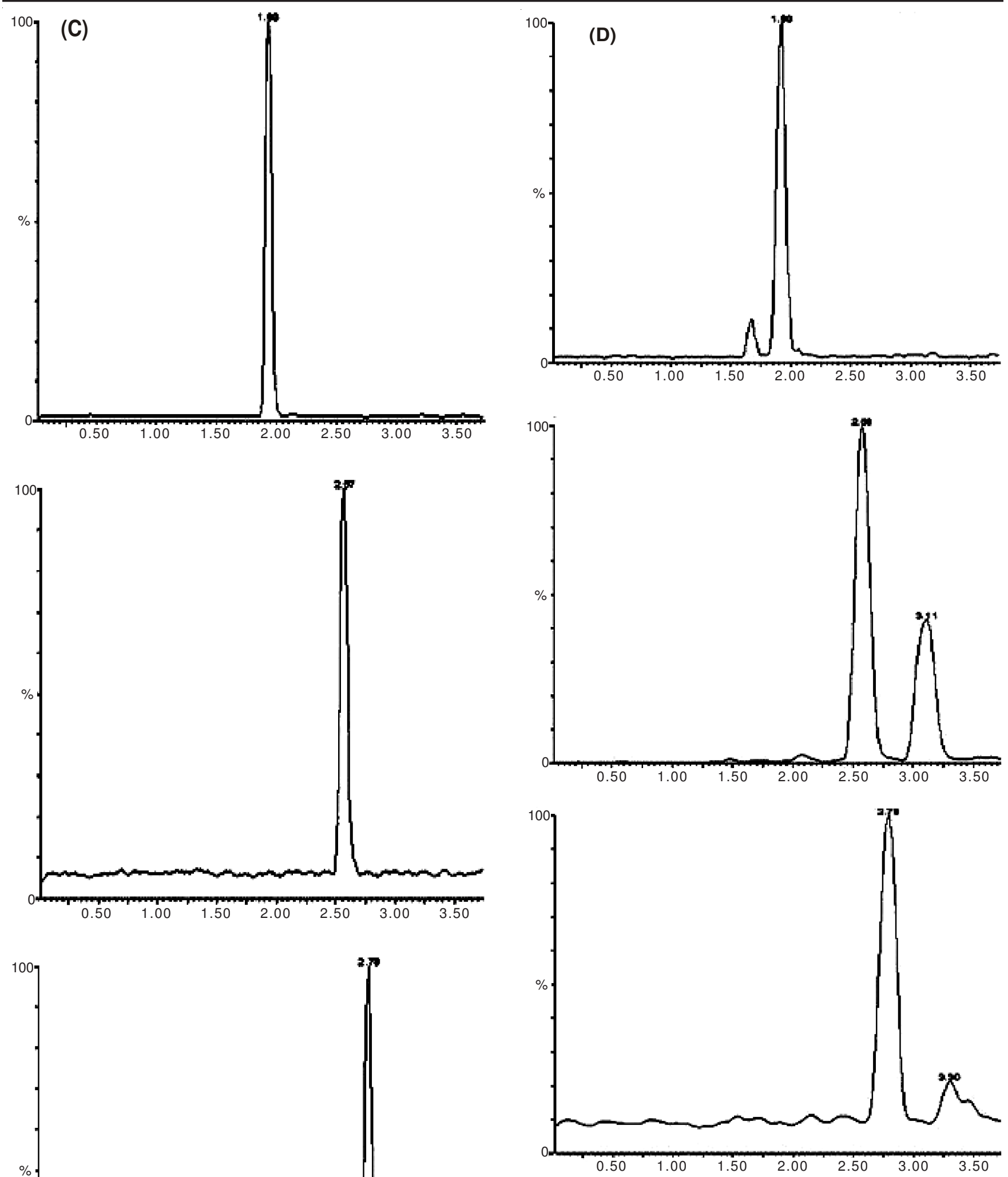

Fig. 2. Representative MRM chromatograms for analytes: upper panel (peimine), middle panel (peiminine) and bottom panel (I.S.): (A) blank plasma; (B) peimine, peiminine $(12 \mathrm{ng} / \mathrm{mL})$ and I.S. dissolved in methanol; (C) blank plasma spiked with peimine, peiminine (12 $\mathrm{ng} / \mathrm{mL}$ ) and I.S.; (D) plasma sample obtained $45 \mathrm{~min}$ after oral administration of extracts of Bulbus fritillariae thunbergii. Chromatographic separation condition: $\mathrm{BEH} \mathrm{C}_{18}$ column $(50 \mathrm{~mm}$ $\times 2.1 \mathrm{~mm}$ i.d., $1.7 \mu \mathrm{m}$ particle size); mobile phase, acetonitrile (A)$10 \mathrm{mM}$ HPLC grade ammonium bicarbonate (adjusted to $\mathrm{pH}=10$ by ammonia water) (B); gradient elution program: $0-0.5 \mathrm{~min}, \mathrm{~B} \%$ $80-32 ; 0.5-2.0 \mathrm{~min}, \mathrm{~B} \% 32-10 ; 2.0-3.0 \mathrm{~min}, \mathrm{~B} \% 10-10 ; 3.0-4.0$ min, B \% 10-80; flow rate, $0.25 \mathrm{~mL} / \mathrm{min}$ 
Method validation: The specificity and selectivity of the proposed method towards endogenous plasma matrix was evaluated in the plasma from the three dogs. In Fig. 2A, no peaks at the retention time of endogenous substances were observed, indicating that no interferences existed in blank dog plasma (prepared by the method described in plasma sample preparation) without drug administration and I.S.

Matrix effects were evaluated based on the comparison of the peak areas of the analytes and I.S. spiked with blank plasma samples with the corresponding peak areas of the same concentration injected directly in methanol (Fig. 2B and Fig. 2C). No obvious matrix effect of the analytes by calculating RSD \% value and comparing with references was observed. The mean extraction recoveries of peimine and peiminine were calculated by analyzing five replicates at three concentrations. The results are shown in Table-2.

\begin{tabular}{ccccc}
\multicolumn{5}{c}{ TABLE-2 } \\
\multicolumn{5}{c}{$\begin{array}{c}\text { RECOVERY AND MATRIX EFFECT OF PEIMINE } \\
\text { AND PEIMININE IN DOG PLASMA }\end{array}$} \\
\hline Items & $\begin{array}{c}\text { Nominal } \\
\text { concentration } \\
(\mathrm{ng} / \mathrm{mL})\end{array}$ & $\begin{array}{c}\text { Peimine } \\
(\%)\end{array}$ & $\begin{array}{c}\text { Peiminine } \\
(\%)\end{array}$ & $\begin{array}{c}\text { Tetrahydropul- } \\
\text { matine } \\
(6 \mathrm{ng} / \mathrm{mL})(\%)\end{array}$ \\
\hline Recovery & 6.0 & 88.4 & 96.4 & 86.5 \\
$(\mathrm{n}=5)$ & 60.0 & 89.5 & 89.5 & 83.8 \\
\hline Matrix & 600.0 & 98.7 & 92.4 & 80.0 \\
effect & 6.0 & 90.2 & 93.1 & 100.1 \\
$(\mathrm{n}=5)$ & 60.0 & 105.5 & 108.1 & 94.3 \\
\hline
\end{tabular}

The calibration curve was linear over the concentration range of $1.0 \mathrm{ng} / \mathrm{mL}$ to $600.0 \mathrm{ng} / \mathrm{mL}$ for both peimine and peiminine. A good linear relationship between peak area ratios and concentrations was established. For peimine, $\mathrm{Y}=0.0167 \mathrm{X}$ $+0.0064\left(r^{2}=0.9992, n=5\right)$ and for peiminine, $\mathrm{Y}=0.0186 \mathrm{X}+$ $0.0027\left(r^{2}=0.9995, n=5\right)$, where $Y$ is the peak area ratio of the analyte to the I.S. and $\mathrm{X}$ is the concentration $(\mathrm{ng} / \mathrm{mL})$ of the analyte. The method lower limits of detection were $0.1 \mathrm{ng} / \mathrm{mL}$ $(\mathrm{S} / \mathrm{N}>3)$ for the two analytes. The LLOQ of the analytes were $0.4 \mathrm{ng} / \mathrm{mL}$ in dog plasma $(\mathrm{S} / \mathrm{N}=10)$, which were sufficient to support the pharmacokinetic studies of the analytes.

The intraday and interday precision and accuracy of peimine and peiminine determined by analyzing the QC samples are presented in Table-3. Each RSD \% and RE \% values were distributed in the range of $-15 \%$ to $15 \%$, indicating that the method was accurate and reliable.

The stability of peimine and peiminine under different storage conditions were tested at three concentrations. Table-4

\begin{tabular}{cccc|cc}
\multicolumn{6}{c}{ TABLE-3 } \\
PRECISION AND ACCURACY VALIDATION RESULTS FOR \\
PEIMINE AND PEIMININE DETERMINATION $(n=5)$
\end{tabular}

lists the stability data of peimine and peiminine in dog plasma. The results indicated that analytes in the plasma were stable under the conditions described previously.

\begin{tabular}{|c|c|c|c|c|c|}
\hline \multicolumn{6}{|c|}{$\begin{array}{c}\text { TABLE-4 } \\
\text { STABILITY OF PEIMINE AND PEIMININE } \\
\text { IN DOG PLASMA }(n=5)\end{array}$} \\
\hline Analyte & Stability & $\begin{array}{l}\text { Concentration } \\
(\mathrm{ng} / \mathrm{mL})\end{array}$ & $\begin{array}{c}\text { Measured } \\
\text { concentration } \\
(\text { mean } \pm \text { SD })\end{array}$ & $\begin{array}{l}\mathrm{RE} \\
(\%)\end{array}$ & $\begin{array}{l}\mathrm{RSD} \\
(\%)\end{array}$ \\
\hline \multirow{12}{*}{ Peimine } & \multirow{3}{*}{$\begin{array}{l}\text { Room temp. } \\
\quad \text { for } 6 \mathrm{~h}\end{array}$} & 6 & $6.3 \pm 0.6$ & 4.4 & 10.2 \\
\hline & & 60 & $65.3 \pm 2.3$ & 8.8 & 3.9 \\
\hline & & 600 & $622.2 \pm 49.9$ & 3.7 & 8.0 \\
\hline & \multirow{3}{*}{$\begin{array}{l}\text { Three freeze- } \\
\text { thaw cycles }\end{array}$} & 6 & $5.9 \pm 0.6$ & -2.1 & 10.0 \\
\hline & & 60 & $61.5 \pm 6.9$ & 2.4 & 11.3 \\
\hline & & 600 & $625.3 \pm 50.2$ & 4.2 & 8.0 \\
\hline & \multirow{3}{*}{$\begin{array}{l}\text { Freeze at } \\
-80^{\circ} \mathrm{C} \text { for } \\
30 \text { days }\end{array}$} & 6 & $6.2 \pm 0.6$ & 3.2 & 10.1 \\
\hline & & 60 & $61.9 \pm 5.2$ & 3.1 & 8.4 \\
\hline & & 600 & $602.6 \pm 49.4$ & 0.4 & 8.2 \\
\hline & \multirow{3}{*}{$\begin{array}{c}\text { Autosampler } \\
\left(10^{\circ} \mathrm{C}\right) \text { for } \\
12 \mathrm{~h} \\
\end{array}$} & 6 & $6.1 \pm 0.7$ & 1.0 & 12.2 \\
\hline & & 60 & $61.1 \pm 7.7$ & 1.9 & 12.5 \\
\hline & & 600 & $623.6 \pm 70.2$ & 3.9 & 11.3 \\
\hline \multirow{12}{*}{ Peiminine } & \multirow{3}{*}{$\begin{array}{l}\text { Room temp. } \\
\quad \text { for } 6 \mathrm{~h}\end{array}$} & 6 & $5.6 \pm 0.4$ & -7.4 & 6.0 \\
\hline & & 60 & $61.2 \pm 3.2$ & 1.9 & 5.2 \\
\hline & & 600 & $610.7 \pm 61.1$ & 1. 8 & 10.0 \\
\hline & \multirow{3}{*}{$\begin{array}{l}\text { Three freeze- } \\
\text { thaw cycles }\end{array}$} & 6 & $5.9 \pm 0.8$ & -1.9 & 13.3 \\
\hline & & 60 & $59.0 \pm 7.5$ & -1.6 & 12.8 \\
\hline & & 600 & $585.5 \pm 58.4$ & -2.4 & 10.0 \\
\hline & \multirow{3}{*}{$\begin{array}{l}\text { Freeze at } \\
-80^{\circ} \mathrm{C} \text { for } \\
30 \text { days }\end{array}$} & 6 & $6.2 \pm 0.5$ & 3.7 & 8.6 \\
\hline & & 60 & $62.3 \pm 5.8$ & 3.9 & 9.3 \\
\hline & & 600 & $617.8 \pm 74.8$ & 3.0 & 12.1 \\
\hline & \multirow{3}{*}{$\begin{array}{l}\text { Autosampler } \\
\left(10^{\circ} \mathrm{C}\right) \text { for } \\
12 \mathrm{~h}\end{array}$} & 6 & $5.8 \pm 0.4$ & -3.0 & 7.4 \\
\hline & & 60 & $62.7 \pm 7.6$ & 4.5 & 12.1 \\
\hline & & 600 & $628.2 \pm 45.4$ & 4.7 & 7.2 \\
\hline
\end{tabular}

Application to a pharmacokinetic study: The validated method was applied at doses of $8.5 \mathrm{mg} / \mathrm{kg}, 10.5 \mathrm{mg} / \mathrm{kg}$ and $12.5 \mathrm{mg} / \mathrm{kg}$, respectively, to analyze the pharmacokinetics in beagle dogs after intragastric administration of the extracts from Bulbus fritillariae thunbergii. The mean plasma concentration-time profiles of peimine and peiminine were illustrated in Fig. $3(n=3)$. The pharmacokinetic data were calculated by non-compartmental method with the aid of PKSolver 2.0. The major pharmacokinetic parameters including $\mathrm{AUC}_{0-\mathrm{t}}$ (area under curve, $\mathrm{AUC}$ ), $\mathrm{AUC}_{0-\infty}, \mathrm{C}_{\max }$ (peak plasma concentration), $\mathrm{T}_{\max }$ (time to peak), $\mathrm{t}_{1 / 2}$ (half-life), $\mathrm{V}_{\mathrm{d}}$ (apparent volume of distribution), CL (total body clearance) and MRT (mean retention time) are displayed in Table-5.

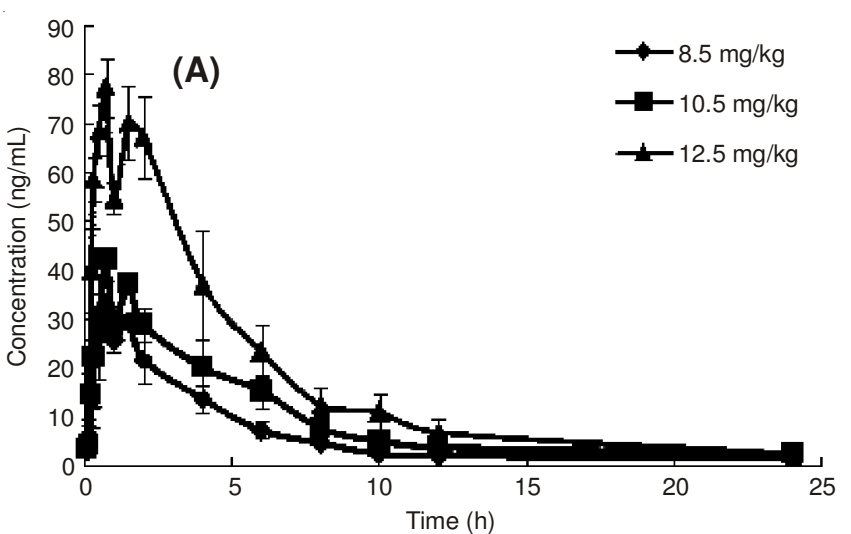




\begin{tabular}{|c|c|c|c|c|c|c|}
\hline \multicolumn{7}{|c|}{$\begin{array}{c}\text { TABLE-5 } \\
\text { PHARMACOKINETIC PARAMETERS AFTER ORAL ADMINISTRATION OF Bulbus fritillariae } \\
\text { thunbergii EXTRACTS AT } 8.5,10.5 \text { AND } 12.5 \mathrm{mg} / \mathrm{kg} \text { TO BEAGLE DOGS }(n=3)\end{array}$} \\
\hline \multirow[t]{2}{*}{ Parameters } & \multicolumn{3}{|c|}{$\begin{array}{l}\text { Peimine }(\text { Mean } \pm \text { SD) } \\
\end{array}$} & \multicolumn{3}{|c|}{ Peiminine $($ Mean \pm SD) } \\
\hline & $8.5 \mathrm{mg} / \mathrm{kg}$ & $10.5 \mathrm{mg} / \mathrm{kg}$ & $12.5 \mathrm{mg} / \mathrm{kg}$ & $8.5 \mathrm{mg} / \mathrm{kg}$ & $10.5 \mathrm{mg} / \mathrm{kg}$ & $12.5 \mathrm{mg} / \mathrm{kg}$ \\
\hline $\mathrm{C}_{\max }(\mathrm{ng} / \mathrm{mL})$ & $35.37 \pm 0.75$ & $42.27 \pm 1.86$ & $77.62 \pm 5.98$ & $18.00 \pm 2.09$ & $23.47 \pm 0.74$ & $35.09 \pm 4.17$ \\
\hline $\mathrm{T}_{\max }(\mathrm{h})$ & $0.75 \pm 0.00$ & $0.75 \pm 0.00$ & $0.75 \pm 0.00$ & $0.67 \pm 0.14$ & $0.75 \pm 0.00$ & $0.75 \pm 0.00$ \\
\hline $\mathrm{T}_{1 / 2}(\mathrm{~h})$ & $4.64 \pm 0.08$ & $5.29 \pm 0.34$ & $5.89 \pm 2.17$ & $7.61 \pm 1.75$ & $9.91 \pm 0.86$ & $9.50 \pm 1.79$ \\
\hline $\operatorname{AUC}_{(0-t)}(\mathrm{ng} \mathrm{h} / \mathrm{mL})$ & $150.23 \pm 15.57$ & $198.06 \pm 5.67$ & $414.61 \pm 80.47$ & $128.70 \pm 12.10$ & $148.01 \pm 13.58$ & $231.62 \pm 23.22$ \\
\hline $\operatorname{AUC}_{(0-\infty)}(\mathrm{ng} \mathrm{h} / \mathrm{mL})$ & $160.87 \pm 16.45$ & $217.71 \pm 8.54$ & $436.98 \pm 89.76$ & $144.38 \pm 10.18$ & $175.01 \pm 16.11$ & $267.39 \pm 31.29$ \\
\hline $\operatorname{MRT}(\mathrm{h})$ & $7.08 \pm 0.15$ & $8.38 \pm 0.73$ & $6.57 \pm 1.33$ & $10.00 \pm 0.98$ & $12.09 \pm 0.57$ & $11.12 \pm 0.79$ \\
\hline $\mathrm{Vd} / \mathrm{F}(\mathrm{L} / \mathrm{kg})$ & $3.56 \pm 0.38$ & $3.68 \pm 0.15$ & $2.40 \pm 0.54$ & $6.56 \pm 1.99$ & $8.65 \pm 1.31$ & $6.42 \pm 1.08$ \\
\hline CL/F (L/h kg) & $0.53 \pm 0.05$ & $0.48 \pm 0.02$ & $0.30 \pm 0.07$ & $0.59 \pm 0.04$ & $0.60 \pm 0.06$ & $0.47 \pm 0.05$ \\
\hline
\end{tabular}

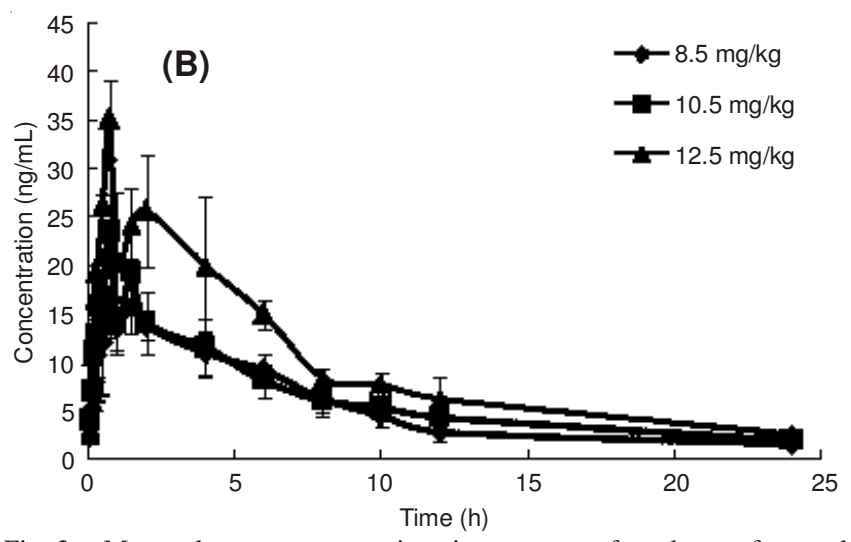

Fig. 3. Mean plasma concentration-time curves of analytes after oral administration of Bulbus fritillariae thunbergii extracts at $8.5(\square)$, $10.5(\square)$ and 12.5 ( $\boldsymbol{\Delta}) \mathrm{mg} / \mathrm{kg}$ to beagle dogs ( $=3)$; (A) peimine; (B) peiminine

Double-peak phenomenon of the dog plasma was found in this study. This result may be caused by various reasons. Enterohepatic circulation ${ }^{13-15}$ is a main factor for the cause of double peaks. Prototype drugs enter the intestines through biliary excretion by simple diffusion or active transport and then reabsorb into the blood circulation, making the blood concentration increase again. This reason can be further confirmed by bile drainage operation or bile duct ligation. Gastrointestinal cycle may be the second main reason that results in the occurrence of double-peak phenomenon ${ }^{16,17}$. Weak alkaline drugs enter the blood in the small intestine and then go into stomach via transmembrane transport, where they exist in forms of ion with high concentration. Drugs change into nonionic forms and reabsorb by the intestine as neutral $\mathrm{pH}$ of intestinal juice in intestine, which produce double peaks. Protein competition and double absorption 14 can also lead to the occurrence of double peaks. However, all the aforementioned reasons are hypothetical and need to be further proved by experiments.

\section{Conclusion}

A sensitive, reliable and robust UPLC-MS/MS quantitative method was developed and successfully applied to the pharma- cokinetic evaluation of peimine and peiminine in dog plasma for the first time. The results indicated that the non-compartmental method was ideal. Double-peak phenomenon of the dog plasma was found in this study. The reasons, such as enterohepatic recirculation and gastrointestinal circulation, should be studied further. In addition, based on the method and results, valuable information was provided for future development of the combination of Bulbus fritillariae thunbergii and antineoplastic drugs.

\section{ACKNOWLEDGEMENTS}

This work was supported by National Science and Technology Major Project of China (2009ZX09103-346).

\section{REFERENCES}

1. P.H. Fan and H.X. Lou, Nat. Prod. Res. Dev., 14, 74 (2001).

2. L. Hou and X.Y. Chen, Chin. J. Bas. Med. TCM, 10, 319 (2004).

3. H.X. Lin, T.Y. Zhang and N. Tan, Med. Recap., 16, 1970 (2010).

4. P. Shu and S.L. Liu, Mod. J. Int. Tradit. Chin. \& West Med., 14, 2884 (2005).

5. H.Y. Li, X.P. Miao and M. Hou, West Chin. Med. J., 23, 1226 (2008).

6. F. Xu and Z.F. Cai, Cent. S. Pharm., 2, 301 (2004).

7. S.W. Qi, Herald Med., 25, 682 (2006).

8. X.L. Yu, H. Ji, C.L. Wang and P. Li, Chin. Tradit. Herbal Drugs, 31, 313 (2000).

9. M.F. Zhang and Y.Q. Shen, Shanghai Med. Pharm. J., 28, 459 (2007).

10. K.W. Hu, X.Y. Chen, M.H. Zuo, L. Hou, T. Sun, T. Li, M. Jiang, W. Li, F. Wang, W. Su and Y.L. Sun, Chin. J. Tradit. Chin. Med. Pharm., 19, 68 (2004).

11. K.W. Hu, H.X. Zheng, J. Qi, L. Hou, M.H. Zuo, X.Y. Chen, Y.L. Sun, Y.F. Xu, X.S. Shao and C.Z. Yang, Chin. J. Hem., 20, 650 (1999).

12. W. Li, K.W. Hu, W. Su, Y.L. Sun, X.Y. Chen and B. Liang, J. Beijing. Univ. TCM, 27, 63 (2004).

13. S.Y. Mi, MS Thesis, Institute of Modern Traditional Chinese Medicine, College of Pharmaceutical Sciences (2006).

14. S.H. Wang, J.X. Chu, Q. Shang, Y.J. Zhang and R.X. Wang, J. Chin. Pharm. Univ., 38, 140 (2007).

15. G.L. Wei, S.H. Xiao and C.X. Liu, Acta. Pharm. Sinica, 35, 721 (2000).

16. S.J. Chen, B. Zhang, Y.M. Yang, Z.S. Dai and F.D. Zeng, Chin. J. Clin. Pharm. Ther, 5, 213 (2000).

17. S.J. Chen, Y.M. Yang, Y.M. Liu, B. Zhang, X.B. Pang and F.D. Zeng, Chin. Pharm. Bull., 17, 225 (2001). 